\title{
Hydroxymethylsilanetriol - A Simple Analog of Silicic Acid
}

\author{
B. Arkles $\cdot$ K. King $\cdot$ K. Pannell
}

Received: 19 December 2012 / Accepted: 7 May 2013 / Published online: 3 July 2013

(C) The Author(s) 2013. This article is published with open access at Springerlink.com

\begin{abstract}
Hydroxymethyltriethoxysilane and hydroxymethyltrimethoxysilane, precursors by hydrolysis to a simple analog of silicic acid, hydroxymethylsilanetriol, were prepared. Hydroxymethyltrialkoxysilanes undergo condensation to form silmethyleneoxide oligomers and dimeric 2,2,5,5-tetraalkoxy-2,5-disila-1,4-dioxanes. Hydroxymethylsilanetriol undergoes condensation reactions similar to silicic acid and readily forms organosilicate structures by sol-gel processing techniques which may be converted at relatively low temperatures to silicon dioxide. Hydroxmethylsilanetriol derived gels were subject to less stresscracking during drying than conventional tetraethoxysilane derived gels, suggesting that $\mathrm{Si}-\mathrm{O}-\mathrm{C}$ bond equilibration during drying provides a mechanism for stress-relief. In screening experiments, hydroxymethylsilanetriol appears to be a competitive inhibitor of the growth of the diatom $C$. fusiformis, a silicate dependent species, which produces silicate structures.
\end{abstract}

Keywords Hydroxymethylsilanetriol $\cdot$ Sol-gel $\cdot$ Diatom

\section{Introduction}

The synthesis of lightweight silicate based ceramic structures by sol-gel techniques and biomimetic processes is

B. Arkles $(\bowtie) \cdot$ K. King

Gelest Inc., 11 East Steel Rd., Morrisville, PA 19067, USA

e-mail: executiveoffice@gelest.com

K. Pannell

Department of Chemistry, University of Texas, El Paso, TX 79968, USA of enormous interest [1,2]. Silicates are the predominant material of the Earth's crust. In neutral water the silicates are soluble to the extent of 70-120 ppm and are in equilibrium with silicic acid, $\mathrm{Si}(\mathrm{OH})_{4}$, a monomeric form of silica [3]. Silicic acid is involved in both mineralization and biomineralization of complex structures. Sol-gel processing, which involves the formation and condensation of silicic acid under low-temperature and aqueous conditions, may be compared to mineralization and biomineralization. Predominantly, sol-gel technology entails the deposition of silicon dioxide from supersaturated solutions, usually formed by hydrolysis of reactive precursors (alkoxysilanes). The systems are unstable, difficult to control, and usually contain byproducts, which must be removed from the matrix. In order for sol-gel technology to achieve its full potential, stress-free, low-shrinkage gels must be produced from highly concentrated silicate solutions containing minimal amounts of byproducts.

Approximately $10 \%$ of the dry weight of all living organisms is mineral structure. The overwhelming biomineralization process is silicification. Diatoms represent 20-25\% of the world's primary biomass production and perform the bulk of the biomineralization for the global biomass [4]. Diatoms are single cell organisms classified with algae which possess a silica "shell" or frustule. Diatoms appear to sequester and store silicic acid at a minimum of 150 -fold greater concentration than the level at which autocondensation of silicic acid occurs [5]. Diatoms synthesize amorphous silicon dioxide structures with remarkable definition [6]. Until recently, the mechanism of silicate sequestration and storage in diatoms remained obscure [7]. While organosilicon intermediates have been postulated for years, none have been identified or isolated. Until 1998, the only organosilicon compound identified from a biological source 
has been a Si-thujaplicine complex extracted from a conifer [8]. With the discovery of a class of proteins denoted "silicateins" in the sponge Tethya aurantia and the associated cDNA sequence, the assembly of silicic acid is now understood to be mediated in many organisms by cathepsin-type proteases [9-11]. Control of silica deposition in diatoms appears to be under further control of a series of hydroxylic, polycationic proteins termed "silaffins", [12, 13]. These insights into biomineralization appear to be vastly important to control the sol-gel processing of silica. The use of short polypeptide sequences of a silaffin-1 precursor protein, rich in serine and lysine residues, has been utilized in the holographic patterning of silica [14]. Similarly the use of polypeptides and synthetic cationic polymers, and long-chain polyamines have demonstrated the ability to direct and control the deposition and morphology of silica [15-17].

In 1955, the first attempt to use organosilicon compounds as possible substrates or inhibitors for silicon metabolism of diatoms was reported [18]. In the experiment, sodium methylsiliconate resin was not found to be utilized by diatoms when it was the sole source of silicon. Since that time, studies of hydrolysis of organosilicate esters have differentiated active sites of serine proteases [19] as well as the biologically mediated transformation of organosilicon compounds [20]. Despite the ability of a variety of enzymatic and non-enzymatic proteins to interact with organosilicates, the in vivo conversion of organosilicates to higher order structures containing organic substitution has not been observed.

Any compound which behaves as a substrate or as a competitive inhibitor for silicic acid biomineralization is a candidate for biomimetic material synthesis as well as a probe of silicate biosynthesis. The object of these studies was to prepare an analog of silicic acid which has greater stability in aqueous solutions than silicic acid and allows greater synthetic control in the preparation of silicate structures. Organosilicon compounds which contained a minimal "organic" content and were likely to have a maximum solution stability were synthesized. The compounds were screened as substrates in the marine diatom Cylindrotheca fusiformis, which produces siliceous frustules. The analog of silicic acid, hydroxymethylsilanetriol, which like silicic acid has four hydroxyl groups and, simplistically, differs only by a methylene group, was the designated target compound for the studies. The condensation behavior of hydroxymethylsilanetriol and its precursor, hydroxymethyltriethoxysilane, to higher order structures both in solution and under sol-gel processing conditions was also considered to be relevant in the event that bioprocessing occurred.

\section{Experimental}

\subsection{Materials}

Choromethyltrichlorosilane, cyanoethyltriethoxysilane, sodium metasilicate (Gelest Inc.), acetonitrile (J.T. Baker HPLC grade), methanol, ethanol, acetic acid, sodium hydroxide (Quaker City Chemical) were used as received. Diatom cultures were maintained from samples originally provided by B. Volcani. Culture nutrients were obtained from MP Biomedical and were used as received.

\subsection{Instrumentation}

Gas chromatograph (GC): Agilent Model 7890A, Restek $30 \mathrm{~m} / 0.25 \mathrm{~mm} \mathrm{ID} / 1 \mathrm{u}$ df column with (5\% diphenylsiloxane)-(95\% dimethylsiloxane) copolymer phase; Mass Spectra (MS): Agilent 5975C; NMR : Jeol $400 \mathrm{MHz}$ for proton and 13C; Brucker $300 \mathrm{MHz}$ for $29 \mathrm{Si}$; Thermogravimetric Analysis: TA Instruments Q50; FTIR: Nicolet Avatar 360.

\subsection{Chloromethyltriethoxysilane}

A 3-neck $1 \mathrm{~L}$ flask equipped with magnetic stirrer, addition funnel, pot thermometer and water-cooled condenser with nitrogen blanket was charged with $555.75 \mathrm{~g}$ ( $410 \mathrm{ml}$ or 3.75 mole, i.e. a $25 \%$ excess) of triethylorthoformate and warmed to $35-40{ }^{\circ} \mathrm{C}$. Chloromethyltrichlorosilane, $183.9 \mathrm{~g}(125.5 \mathrm{ml}, 1 \mathrm{~mole})$ was added dropwise. At about $1 / 3$ addition, evolution of ethylchloride became evident. After the addition was complete the mixture was heated to reflux until ethylchloride evolution slowed. Volatile components were removed from the mixture by heating to a pot temperature of $160{ }^{\circ} \mathrm{C}$ and then, after the mixture cooled to room temperature, applying $15 \mathrm{~mm} \mathrm{Hg}$ vacuum. A distillation head and column were mounted on the flask and the mixture was fractionated. The product fraction, identified by IR as chloromethyltriethoxysilane, was collected at $82-5{ }^{\circ} \mathrm{C} / 15 \mathrm{~mm} \mathrm{Hg}$. Purity (GC): $98.3 \%$; Yield: $92 \%$. Physical Properties- boiling point: $92-5{ }^{\circ} \mathrm{C} / 15 \mathrm{~mm} \mathrm{Hg}$; density: 1.048 at $20^{\circ} \mathrm{C}$; $\mathrm{nD} 25$ : 1.4069; IR $\mathrm{cm}^{-1}$ - strong: 2980, 1085, 801; 1H NMR $\left(\mathrm{CDCl}_{3}, \delta\right): 3.87\left(\mathrm{~m}, \mathrm{CH}_{2}, 6 \mathrm{H}\right), 2.77,\left(\mathrm{~m}, \mathrm{CH}_{2}, 2 \mathrm{H}\right), 1.22$ (m, $\left.\mathrm{CH}_{3}, 9 \mathrm{H}\right) \mathrm{GC}-\mathrm{MS} \mathrm{m} / \mathrm{z}$ (\% rel. int.): $211.1\left(\mathrm{M}^{+}-1,1.2\right)$, $163.1\left(\mathrm{Si}(\mathrm{OEt})_{3}^{+}, 100\right)$

\subsection{Acetoxymethyltriethoxysilane}

A 2 L 3-neck flask equipped with mechanical stirrer, pot thermometer and reflux condenser blanketed with nitrogen was charged with 11 of acetonitrile, $1 \mathrm{~g}$ of 18 -crown- 6 , 
$196 \mathrm{~g}$ ( 2 mole or a $100 \%$ excess) of potassium acetate and $212.75 \mathrm{~g}$ ( 1 mole) of chloromethyltriethoxysilane. With agitation the mixture was brought to reflux for four hours and then the temperature reduced to just below reflux (pot temperature $80-84^{\circ} \mathrm{C}$ ). The reaction progress was monitored by GC. A full week of stirring was required to achieve about $90 \%$ conversion. The reaction mixture was allowed to cool to room temperature. The supernatant was filtered from the salts through a Buchner funnel. The salts were washed with an additional $400 \mathrm{ml}$ of acetonitrile and filtered on a Buchner funnel. The combined supernatants were stripped at atmospheric pressure, allowing the pot temperature to reach $120^{\circ} \mathrm{C}$. The formation of new high boiling products observed by GC suggested that atmospheric distillation of the product should not be attempted. The mixture was distilled at $15 \mathrm{~mm} \mathrm{Hg}$ through a heated glass helix packed column. The overall recovered yield was $81 \%$. A fraction of $104 \mathrm{~g}$ assayed at $99+\%$ by GC and was employed for physical property and spectroscopic evaluation. Physical Properties- boiling point: $106^{\circ} \mathrm{C} / 15 \mathrm{~mm}$; density, $25^{\circ} \mathrm{C}$ : 1.0042; nD20: 1.4092; IR cm ${ }^{-1}$-strong: 2977, 1746, 1080; NMR-1H $\left(\mathrm{CDCl}_{3}, \delta\right): 3.77$ (q, $\left.\mathrm{CH}_{2-}, J=20 \mathrm{~Hz}, 2 \mathrm{H}\right)$, 3.69 (s, $\left.\mathrm{CH}_{2}, 2 \mathrm{H}\right), 1.96$ (s, $\left.\mathrm{CH}_{3}, 3 \mathrm{H}\right), 1.13$ (t, $\mathrm{CH}_{3}, \mathrm{~J}=$ $16 \mathrm{~Hz}, 9 \mathrm{H})$; 13C: 58.98, 51.49, 28.28, 19.36; 29Si: -54.2; GC-MS m/z (\% rel. int.): $236.1\left(\mathrm{M}^{+}, 3.7\right), 191.1\left(\mathrm{CH}_{3} \mathrm{C}=\right.$ $\left.\mathrm{OOCH}_{2} \mathrm{Si}(\mathrm{OEt})_{2}^{+}, 100\right)$

\subsection{Hydroxymethyltriethoxysilane}

A $250 \mathrm{ml}$ single neck round bottom flask was charged with $42 \mathrm{~g}$ (0.178 mole) of acetoxymethyltriethoxysilane from above and $100 \mathrm{ml}$ (78.5 g, 1.7 mole) of 2B denatured ethanol containing $0.16 \mathrm{~g}$ of concentrated sulfuric acid. The flask was equipped with a short unpacked column and distillation head protected with a nitrogen blanket. The mixture was stirred at reflux for $24 \mathrm{~h}$. Approximately $50 \mathrm{ml}$ of distillate was removed. The distillate had the characteristic odor, confirmed by IR, of ethylacetate. An additional $50 \mathrm{ml}$ of ethanol was added to the flask and the process repeated twice. The mixture was stripped to a pot temperature of about $100{ }^{\circ} \mathrm{C}$ at $1 \mathrm{~mm}$. A clear polymer of hydroxymethyltriethoxysilane, identified as poly(diethoxysilmethylene oxide) formed. The polymer had weak IR absorption at $1745 \mathrm{~cm}^{-1}$ indicating the presence of 2-6\% acetoxymethyl groups.

The above experiment was repeated except that instead of stripping the reaction mixture in vacuum $0.15 \mathrm{~g}$ of sodium bicarbonate was added and $75 \mathrm{ml}$ of distillate was removed from the mixture. $75 \mathrm{ml}$ of additional alcohol was added. The mixture was filtered. Distillation was resumed. Sufficient material was removed to reduce the mass of the reaction to $70 \mathrm{~g}(50 \%)$. GC analysis of the solution showed a large component with an extrapolated boiling point of 210-220 ${ }^{\circ} \mathrm{C}$, but higher boiling components were significant. Physical Properties- boiling point: unstable; (extrapolated atmospheric b.p.: $\left.210-220{ }^{\circ} \mathrm{C}\right)$; IR $\mathrm{cm}^{-1}$-strong: 3390, 2976, 2885, 1188, 1079, 982; NMR-29Si: -52.9 (see Fig. 1).

\subsection{Chloromethyltrimethoxysilane}

A 3-neck 1 L flask equipped with magnetic stirrer, addition funnel, pot thermometer and water-cooled condenser with nitrogen blanket was charged with $398 \mathrm{~g}(410 \mathrm{ml}$ or 3.75 mole, i.e. a threefold excess) of trimethylorthoformate (TMOF) and warmed to $35-40{ }^{\circ} \mathrm{C}$. Chloromethyltrichlorosilane, $73.5 \mathrm{~g}$ (50.2 $\mathrm{ml}$ or $0.4 \mathrm{~mole})$, was added dropwise. At about 1/4 addition, evolution of methylchloride became evident. After the addition was complete the mixture was heated to reflux until methylchloride evolution slowed. The condenser was replaced with a short $(150 \mathrm{~mm})$ Vigreux column and distillation head.

Chloromethyltrimethoxysilane was isolated by distillation in $92 \%$ yield. Physical Properties- boiling point: $157{ }^{\circ} \mathrm{C}$; density, $20{ }^{\circ} \mathrm{C}$ : 1.125 ; nD20: 1.4070 ; IR $\mathrm{cm}^{-1}$ strong: 2949, 2847, 1196, 1092, 834; $1 \mathrm{H} \mathrm{NMR}\left(\mathrm{CDCl}_{3}, \delta\right)$ : 3.59 (s, $\left.\mathrm{CH}_{3}, 9 \mathrm{H}\right), 2.76$ (s, $\left.\mathrm{CH}_{2}, 2 \mathrm{H}\right) \mathrm{GC}-\mathrm{MS} \mathrm{m} / \mathrm{z}$ (\% rel. int.): $169.0\left(\mathrm{M}^{+}-1,0.2\right), 121.1\left(\mathrm{Si}(\mathrm{OMe})_{3}^{+}, 100\right)$

\subsection{Acetoxymethyltrimethoxysilane}

A single neck round bottom flask equipped with heating mantle, magnetic stirrer and a nitrogen protected reflux condenser was charged sequentially with $250 \mathrm{ml}$ acetonitrile, $42.7 \mathrm{~g}$ (0.25 mole) chloromethyltrimethoxysilane from above, $0.25 \mathrm{~g} 18$-crown- 6 and $49.1 \mathrm{~g}$ ( 0.5 mole or a $100 \%$ excess) potassium acetate. The mixture was heated to reflux. After 4 days GC analysis indicated $>90 \%$ conversion of the chloromethyltrimethoxysilane. The volume of salts in the flask was also reduced. The mixture was allowed to cool to room temperature and salts removed by being filtered using a Buchner funnel and then distilled through a $25 \mathrm{~cm} \mathrm{14/20}$ glass helix packed column. The best distillation cut boiled at $188-191{ }^{\circ} \mathrm{C}$ at $91.5 \%$ purity. Redistillation at $190{ }^{\circ} \mathrm{C}$ gave $95.5 \%$ purity and yielded $22 \mathrm{~g}$. There appeared to be some product degradation during the distillation. Properties of the distillate were in agreement with earlier literature [21]. Physical Properties- boiling point: $190{ }^{\circ} \mathrm{C}$; density: 1.08; nD20: 1.4031; IR cm ${ }^{-1}$-strong: 2949, 1740, 1235, 1100; 1H NMR $\left(\mathrm{CDCl}_{3}, \delta\right): 3.57\left(\mathrm{~s}, \mathrm{CH}_{2}, 2 \mathrm{H}\right), 3.38$ (s, $\left.\mathrm{CH}_{3}, 9 \mathrm{H}\right), 1.84$ (s, $\left.\mathrm{CH}_{3}, 3 \mathrm{H}\right)$; GC-MS m/z (\% rel. int.): $194.1\left(\mathrm{M}^{+}, 0.2\right), 121.1\left(\mathrm{Si}(\mathrm{OMe})_{3}^{+}, 100\right)$ 
Fig. 1

Hydroxymethyltriethoxysilane in ethanol, [29] Si NMR

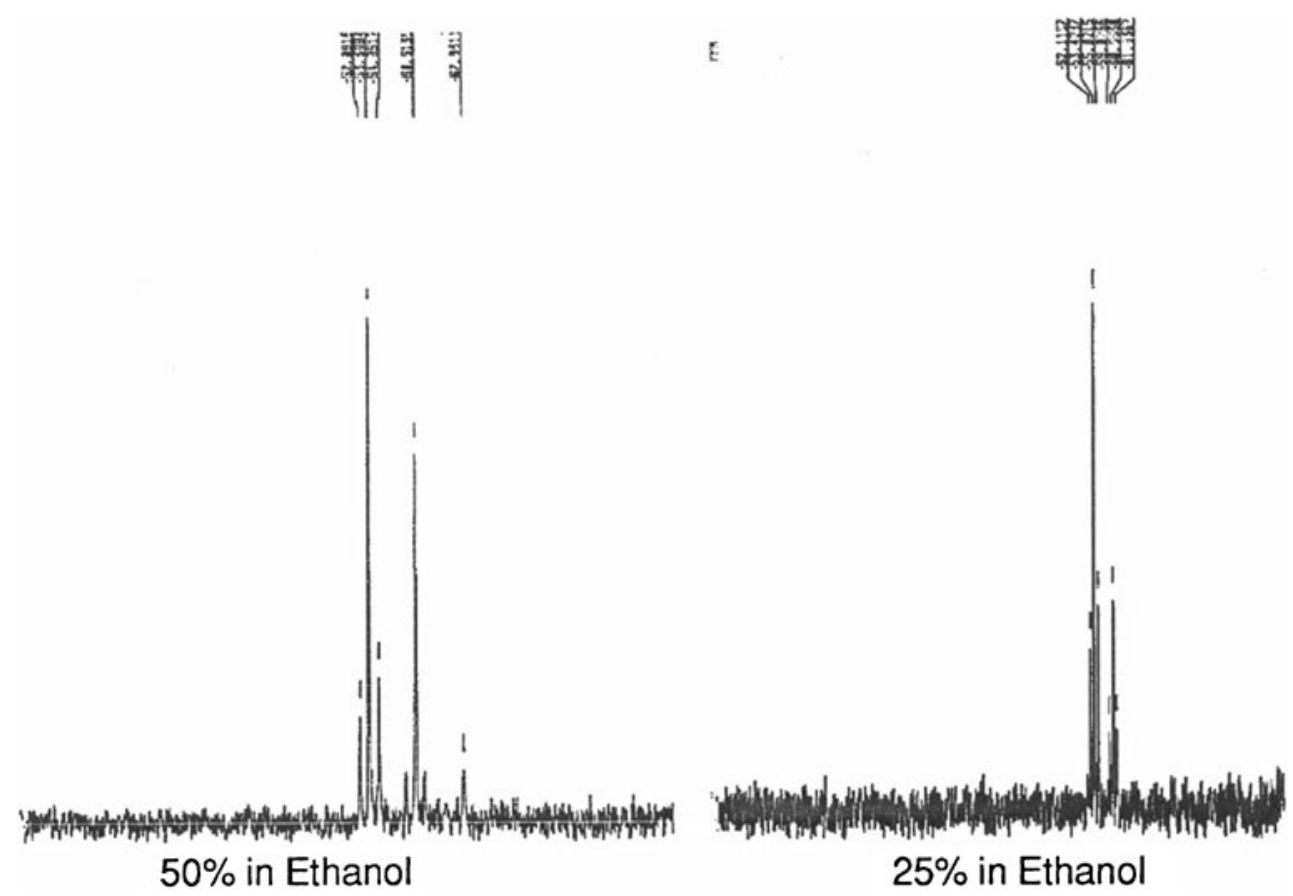

\subsection{Hydroxymethyltrimethoxysilane}

A $100 \mathrm{ml}$ single neck round bottom flask was charged with $17.8 \mathrm{~g}(0.1 \mathrm{~mole})$ of acetoxymethyltrimethoxysilane from above, and $30 \mathrm{ml}$ of methanol (23.7 $\mathrm{g}$ or a $600 \%$ excess) containing about $0.1 \mathrm{~g}$ of concentrated sulfuric acid. The flask was equipped with a short glass helix packed column and distillation head protected with a nitrogen blanket. The mixture was stirred at reflux for $4 \mathrm{~h}$. Approximately $12 \mathrm{ml}$ of distillate was removed. The distillate had the characteristic odor, confirmed by IR, of methylacetate. An additional $12 \mathrm{ml}$ of methanol was added to the flask and the transesterification process repeated. $0.1 \mathrm{~g}$ of potassium bicarbonate was added and $30 \mathrm{ml}$ of distillate was removed from the mixture. The mixture was filtered. The clear residue weighed $12.65 \mathrm{~g}$. Less than $5 \%$ volatile components were observed by GC, suggesting substantial condensation to dimeric and polymeric species. Thin films of the product hydrolyzed on standing in air to form clear, hard films.

Physical properties- hydroxymethyltrimethoxysilane/ poly(dimethoxysilmethylene oxide) mixture: Boiling point: unstable; IR- strong: 3424, 2949, 2845, 1193, 1077, 837

2.9 Carboxymethyltriethoxysilane, (triethoxysilylmethyl)formate

A single neck $100 \mathrm{ml}$ flask equipped with magnetic stirrer and reflux condenser blanketed with nitrogen, was charged with $45 \mathrm{ml}$ acetonitrile, $0.26 \mathrm{~g}(0.001 \mathrm{M}) 18$-crown- $6,12.6 \mathrm{~g}$
(0.15 mole, a $50 \%$ excess) potassium formate and $21.27 \mathrm{~g}$ (0.1 mole) chloromethyltriethoxysilane. The mixture was heated to reflux. Reaction progress was monitored by G.C. After $24 \mathrm{~h}$ about $50 \%$ conversion was observed. Reaction progressed to about $75 \%$ after $48 \mathrm{~h}$, and to about $80 \%$ after $72 \mathrm{~h}$. The mixture began to show build-up of high boiling compounds. The mixture was filtered through glass wool to remove salts. The mixture was fractionated at reduced pressure. In the first stage acetonitrile was removed at about $100 \mathrm{~mm} \mathrm{Hg}$. Vacuum pressure was reduced. The product fraction distilled at $93^{\circ} \mathrm{C} / 13 \mathrm{~mm}-98^{\circ} \mathrm{C} / 17 \mathrm{~mm} \mathrm{Hg}$; yield: $8.8 \mathrm{~g}(40 \%)$. Physical Properties- boiling point: $93^{\circ} \mathrm{C} / 13 \mathrm{~mm} \mathrm{Hg}$; IR cm ${ }^{-1}$-strong: 2977, 2930, 1735, 1444 , $1393,1290,1100$. In order to evaluate aqueous stability a solution of $0.5 \mathrm{~g}$ carboxymethyltriethoxysilane, $0.5 \mathrm{~g}$ of ethanol and $4.0 \mathrm{~g}$ of distilled water was prepared. The solution was stable for greater than 1 month.

\subsection{Hydroxymethyltriethoxysilane (Alternate Synthesis)}

A $50 \mathrm{ml}$ single neck round bottom flask was charged with $4.4 \mathrm{~g}$ (0.02 mole) of carboxymethyltriethoxysilane from above and $10 \mathrm{~g}$ ( 0.22 mole, about 10 fold excess) of 2B denatured ethanol containing $0.02 \mathrm{~g}$ of sulfuric acid. The flask was equipped with a $150 \mathrm{~mm}$ packed column and distillation head protected with a nitrogen blanket. The mixture was stirred at $50-60^{\circ} \mathrm{C}$ for $25 \mathrm{~h}$. Approximately $5 \mathrm{~g}$ of ethyl formate/ethanol was removed by distillation. An additional $5 \mathrm{~g}$ of ethanol was added to the flask. After stirring the mixture at $50-60{ }^{\circ} \mathrm{C}$ for $2 \mathrm{~h}, 0.05 \mathrm{~g}$ of sodium bicarbonate 
Table 1 Tetraethoxysilane derived sols (control)

\begin{tabular}{lllll}
\hline Compound & M.W. & g & ml & mole \% \\
\hline tetraethoxysilane & 208.33 & 22.7 & 24.3 & 10.9 \\
ethanol & 46.07 & 27.36 & 34.6 & 54.9 \\
water & 18.02 & 3.78 & 3.78 & 21.0 \\
$\mathrm{HCl}$ & 36.46 & $0.365(0.1 \mathrm{ml}$ of $1 \mathrm{M}$ sol'n) & \\
\hline
\end{tabular}

The compounds were mixed ( $\mathrm{HCl}$ last) and stirred for $20 \mathrm{~min}$. Water was added in aliquots listed and $15 \mathrm{ml}$ of solution was removed and cast for gel formation

was added. The mixture was stirred $1 \mathrm{~h}$ additional without heating, and then the solution was decanted through glass wool to remove sodium bicarbonate/sodium sulfate. The mixture was returned to the flask and distillation was resumed. Sufficient material was removed to reduce the mass of the reaction to $7.8 \mathrm{~g}$ (about $50 \%$ product concentration). As in the case of product prepared by transesterifaction of the acetate, GC of the solution showed a large component with an extrapolated boiling point of $210-220^{\circ} \mathrm{C}$, but higher peaks were significant.

\subsection{Carboxyethylsiliconate, Sodium Salt}

Cyanoethyltriethoxysilane (0.05 mole, $10.9 \mathrm{~g}$ ), deionized water $(100 \mathrm{~g})$ and sodium hydroxide $(0.1$ mole, $4.0 \mathrm{~g})$ were charged to a $250 \mathrm{ml}$ single neck round bottom flask equipped with a magnetic stirrer and reflux condenser and immediately heated to reflux. The odor of ammonia was evident within 15 min. The mixture was refluxed overnight. At the end of this time, the mixture still retained the odor of ammonia. A distillation head was mounted on the flask and $57 \mathrm{~g}$ of water was removed by distillation-initial bp $98^{\circ} \mathrm{C}$, reaching $100{ }^{\circ} \mathrm{C}$ after about $10 \mathrm{ml}$ were removed. After cooling, the mixture was diluted with additional deionized water to a total volume of $146 \mathrm{ml}$ to give a silicon equivalent of $1 \mathrm{~g}: 100 \mathrm{ml}$. The solution had a $\mathrm{pH}$ of $12-13$.

\subsection{Gel Studies}

Gels were formed from acetoxymethyltriethoxysilane, hydroxymethyltriethoxysilane and tetraethoxysilane (control) in a two-step hydrolysis method. Initially a mixture of silane: water: ethanol: $\mathrm{HCl}$ was prepared at a ratio of 1:1.5:5:1 $\times 10^{-3}$ and stirred for $30 \mathrm{~min}$. An additional 1.5 to 3.2 equivalents of water was added. The solutions were poured into $50 \mathrm{~mm}$ round glass petri dishes and stored quiescently. Clear gels formed in 12-24 h. After $48 \mathrm{~h}$, the gels were dried at $110^{\circ} \mathrm{C}$ (Tables $1,2,3,4,5$ and 6).

The dried gels formed from acetoxymethyltriethoxysilane were stable in water indefinitely, but in contrast to gels formed from tetraethoxysilane, dissolved in cold sulfuric acid overnight. Thermogravimetric analysis of dried gels in air at $10{ }^{\circ} \mathrm{C} / \mathrm{min}$ showed gradual loss of approximately $5 \%$ of weight up to $200{ }^{\circ} \mathrm{C}$, presumably associated with further condensation and loss of water. At higher temperatures, the rate of weight loss increased to a maximum at $430{ }^{\circ} \mathrm{C}$, finally stabilizing at $670{ }^{\circ} \mathrm{C}$ at $60 \%$ of initial dry weight (Tables 7).

During the initial $24 \mathrm{~h}$, clear gels formed from hydroxymethyltriethoxysilane over the entire range of conditions tested in contrast to tetraethoxysilane and acetoxymethyltriethoxysilane. It was possible to generate thinner films with fewer fractures with hydroxymethyltriethoxysilane than tetraethoxysilane. The dried gels formed from hydroxymethyltriethoxysilane were indefinitely stable to water and were not dissolved by cold sulfuric acid. Thermogravimetric analysis of dried gels in air at $10{ }^{\circ} \mathrm{C} / \mathrm{min}$ showed gradual loss of approximately $5 \%$ of weight up to $250{ }^{\circ} \mathrm{C}$, presumably associated with further condensation and loss of water. Weight loss stabilized at $670{ }^{\circ} \mathrm{C}$ at approximately $80 \%$ of initial dry weight. The sintered product was an amber glass. Elemental analysis indicated $>99 \%$ $\mathrm{SiO}_{2}$.

\subsection{Culture Studies}

All diatom culture studies were in either bisphenol A polycarbonate or polymethylpentene containers. Water was $>10 \mathrm{M}$-ohm prepared by deionization in a polymer based system. Cultures of $C$. fusiformis were established in $50 \mathrm{ml}$ of media. In evaluating the effect of silicon containing species, $0.5 \mathrm{ml}$ of stock solution was added to $50 \mathrm{ml}$ of medium resulted in $10 \mathrm{ppm}$ of Si present. The media of Paul and Volcani $[22,23]$ as modified by Guilard "f/2" [24] was employed.

Table 2 Tetraethoxysilane derived gels (control)

\begin{tabular}{|c|c|c|c|c|c|}
\hline Sample \# & Walter aliquot & $14 \mathrm{~h}$ & $24 \mathrm{~h}$ & $38 \mathrm{~h}$ & $110^{\circ} \mathrm{C}$ at $48 \mathrm{~h}$ \\
\hline 1 & $6 \mathrm{ml}$ & gel/cracks & shatter & shatter/warp & micro-cracks \\
\hline 2 & $6 \mathrm{ml}$ & gel/cracks & cracks & large pieces & micro-cracks \\
\hline 3 & $6 \mathrm{ml}$ & gel/cracks & cracks & large pieces & cracks \\
\hline 4 & $6 \mathrm{ml}$ & liquid & gel & shatter & cracks \\
\hline
\end{tabular}


Table 3 Acetoxymethyltriethoxysilane derived sols (monoorganoalkoxysilane control)

\begin{tabular}{lllr}
\hline Compound & M.W. & g & ml \\
\hline acetoxymethyltriethoxysilane, $50 \%$ in ethanol & 236.34 & 19.5 & mole \% \\
ethanol & 46.07 & $2.812 .5 \mathrm{~g}$ (including ethanolic component of silane) & 10.6 \\
water & 18.02 & 1.35 & 69.9 \\
$\mathrm{HCl}$ & 36.46 & 0.146 & 19.4 \\
\hline
\end{tabular}

The compounds were mixed ( $\mathrm{HCl}$ last) and stirred for $20 \mathrm{~min}$. Water was added in aliquots listed and $6.75 \mathrm{ml}$ of solution was removed and cast for gel formation

Table 4 Acetoxymethyltriethoxysilane derived gels (monoorganoalkoxysilane control)

\begin{tabular}{llllll}
\hline Sample \# & Water aliquot & $14 \mathrm{~h}$ & $24 \mathrm{~h}$ & $38 \mathrm{~h}$ & $110{ }^{\circ} \mathrm{C}$ at $48 \mathrm{~h}$ \\
\hline 1 & $2.75 \mathrm{ml}$ & gel/curl & few cracks & large pieces & micro-cracks \\
2 & $2.75 \mathrm{ml}$ & liquid & gel-opalescent & large pieces & micro-cracks \\
3 & $2.75 \mathrm{ml}$ & liquid/opaque & liquid/opaque & slight gel/dry-out & no cracks \\
4 & $1.4 \mathrm{ml}$ & liquid & liquid & dry-opaque & white solid \\
5 & $1.4 \mathrm{ml}$ & liquid & liquid & dry-opaque & white solid \\
\hline
\end{tabular}

Table 5 Hydroxymethyltriethoxysilane derived sols

\begin{tabular}{lllr}
\hline Compound & M.W. & $\mathrm{g}$ & $\mathrm{ml}$ \\
\hline hydroxymethyltriethoxysilane, 50\% in ethanol & 195.31 & 19.5 & Mole \% \\
ethanol & 46.07 & $2.8(12.5$ g including ethanolic component of silane $)$ & 12.6 \\
water & 18.02 & 1.35 & 68.4 \\
$\mathrm{HCl}$ & 36.46 & 0.146 & $0.04 \mathrm{ml} 1 \mathrm{M} \mathrm{sol'n}$ \\
\hline
\end{tabular}

The compounds were mixed ( $\mathrm{HCl}$ last) and stirred for $20 \mathrm{~min}$. Water was added in aliquots listed and $7.5 \mathrm{ml}$ of solution was removed and cast for gel formation

Table 6 Hydroxymethyltriethoxysilane derived gels

\begin{tabular}{|c|c|c|c|c|c|}
\hline Sample \# & Water Aliquot & $14 \mathrm{~h}$ & $24 \mathrm{~h}$ & $38 \mathrm{~h}$ & $110^{\circ} \mathrm{C}$ at $48 \mathrm{~h}$ \\
\hline 1 & $2.75 \mathrm{ml}$ & gel/opalescent (no cracks) & clear/cracks & clear/large pieces & powder \\
\hline 2 & $2.75 \mathrm{ml}$ & gel/clear (no cracks) & clear/cracks & clear/large pieces & powder \\
\hline 3 & $2.75 \mathrm{ml}$ & liquid & gel/clear & gel/clear/cracks & clear/cracks \\
\hline 4 & $2.75 \mathrm{ml}$ & liquid & gel/clear/cracks & gel/clear/cracks & clear/cracks \\
\hline 5 & $1.40 \mathrm{ml}$ & liquid & gel/clear/cracks & gel/clear/cracks & clear/cracks \\
\hline
\end{tabular}

Table 7 Summary of thermogravimetric analysis and sulfuric acid resistance of gels dried at $110^{\circ} \mathrm{C}$

\begin{tabular}{lllll}
\hline Precursor & Weight loss $<200^{\circ} \mathrm{C}$ & Weight loss $>200{ }^{\circ} \mathrm{C}$ & Maximum rate of weight loss & Sulfuric acid (98\%) solubility \\
\hline Hydroxymethyltriethoxysilane & $4 \%$ & $15 \%$ & $415^{\circ} \mathrm{C}$ & insoluble \\
Acetoxymethyltriethoxysilane & $4 \%$ & $35 \%$ & $440{ }^{\circ} \mathrm{C}$ & soluble \\
Tetraethoxysilane & $15 \%$ & $5 \%$ & & soluble \\
\hline
\end{tabular}


Scheme 1

Hydroxymethyltriethoxysilane condensates<smiles>CCO[Si](CO)(CO[Si](CO)(OCC)OCC)OC[Si](OCC)(OCC)OCC</smiles>

SIMPLE OLIGOMERS

POLYMER

One liter of solution contained the following macronutrients (>0.002 g/l): $\mathrm{NaCl}, \mathrm{MgSO}_{4}, \mathrm{MgCl}_{2}, \mathrm{CaCl}_{2}$, glycylglycine, $\mathrm{KCl}, \mathrm{KNO}_{3}, \mathrm{NaNO}_{3}, \mathrm{~B}(\mathrm{OH})_{3}$, ethylenediaminetetracetic acid (EDTA), $\mathrm{K}_{2} \mathrm{HPO}_{4}$, and the following micronutrients ( $<10 \mathrm{uM} / \mathrm{l}$ of medium): $\mathrm{Zn}, \mathrm{Mn}, \mathrm{Mo}$, $\mathrm{Co}, \mathrm{Fe}$, cyanocobolamine, biotin, thiamine. The $\mathrm{pH}$ was adjusted to 8.0-8.2. Free growing cultures utilized $0.025 \mathrm{~g}$ $\mathrm{Na}_{2} \mathrm{SiO}_{3} / \mathrm{l}$.

\section{Results and Discussion}

\subsection{Compound Synthesis}

The synthesis of chloromethyltrialkoxysilanes synthesized in these studies utilized orthoesters in the esterification reaction which was more convenient and provided higher yields at laboratory-scale than the direct esterification previously reported [25]. Properties were in close agreement with those previously reported.

Acetoxymethyltrialkoxysilanes, carboxymethyltrimethoxysilane, and hydroxymethyltriethoxysilane and its' polymeric derivatives as well as sodium carboxyethylsiliconate, a screening control for diatom growth studies, were synthesized.

Acetoxymethyltriethoxysilane and hydroxymethyltriethoxysilane and their methoxy analogs were prepared according to the following equation, which modifies a method reported for trialkysilyl alcohols [26].

Carboxyethylsiliconate was prepared according to the following equation, which is a modification of the synthesis previously reported [27].

$$
\begin{aligned}
& \mathrm{NCCH}_{2} \mathrm{CH}_{2} \mathrm{Si}\left(\mathrm{OC}_{2} \mathrm{H}_{5}\right)_{3}+3 \mathrm{H}_{2} \mathrm{O}+2 \mathrm{NaOH} \rightarrow \\
& \mathrm{Na}^{+-} \mathrm{OOCCH}_{2} \mathrm{CH}_{2} \mathrm{Si}(\mathrm{OH})_{2} \mathrm{O}^{-} \mathrm{Na}^{+}+\mathrm{NH}_{3}+3 \mathrm{C}_{2} \mathrm{H}_{5} \mathrm{OH}
\end{aligned}
$$

Scheme 2 Mass spectra of the cyclic dimer

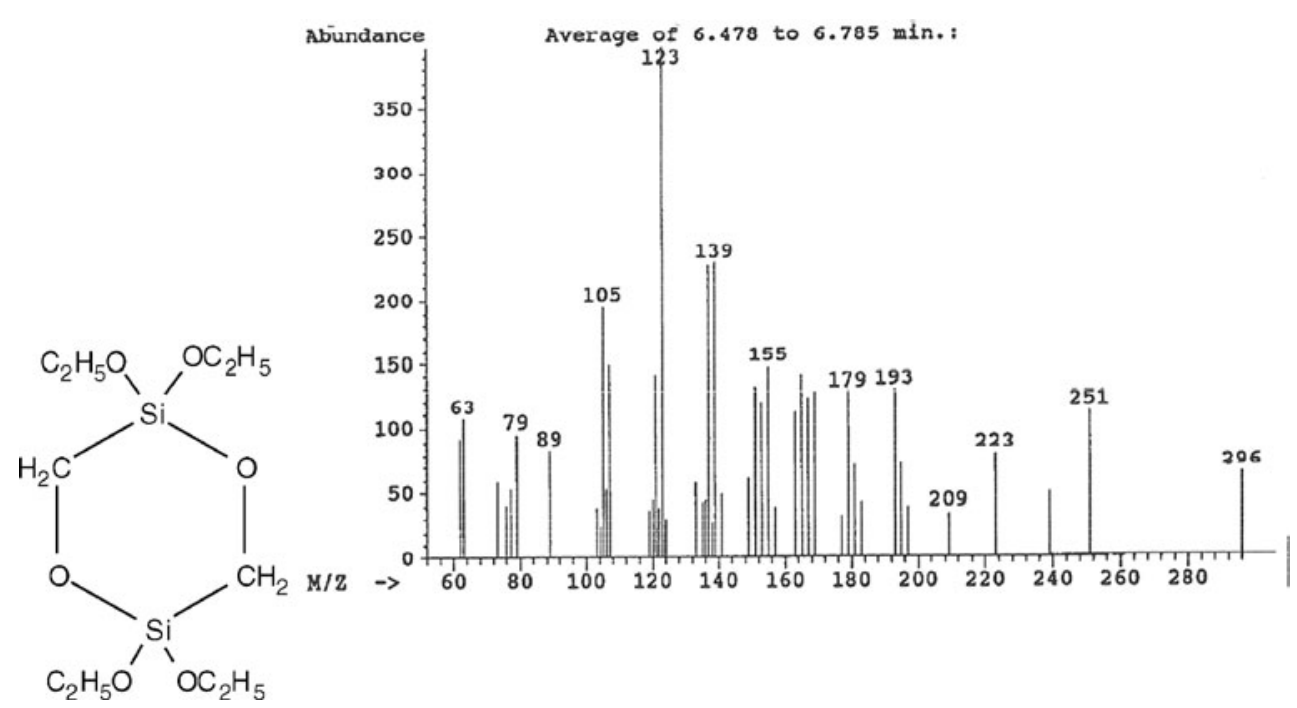




\subsection{Compound Characterization and Behavior}

Hydroxymethyltriethoxysilane was not stable in pure form, but equilibrated in an ethanol solution with various oligomers and polymers (Scheme 1). At low concentrations of hydroxymethyltriethoxysilane in ethanol the oligomers were of low enough molecular weight to be observed by GC. At high concentrations of hydroxymethyltriethoxysilane the formation of polymers was observed by 29Si FTNMR. Conversely, as shown in NMR Fig. 1, a clear reduction in the amount of oligomers including the elimination of a species at $-67.8 \mathrm{ppm}$, occurred when a $50 \%$ solution of hydroxymethylsilanetriol was diluted to $25 \%$ with ethanol.

If ethanol was entirely removed from the equilibrium mixture, a clear rubbery insoluble polymer, poly(diethoxysilmethyleneoxide) formed. The polymer was insoluble in toluene and tetrahydrofuran, but swelled in methylene chloride. On exposure to ethanol the insoluble polymer equilibrated to soluble low molecular weight species. The degree of polymerization in freshly prepared solutions was nearly proportional to the mole ratio of hydroxymethyltriethoxysilane to ethanol. Aged solutions showed increasing concentrations of the cyclic dimer, 2,2,5,5-tetraethoxy-2,5disila-1,4-dioxane, mass ion 296 by GC-MS Fig. 2.

The compound exhibited a minor but significant molecular ion. The mass spectral fragmentation pattern exhibited two basic trends and elucidated the ceramic conversion mechanism observed in thermogravimetric analysis (TGA). Subsequent to the loss of an initial ethoxy group, the ion $\mathrm{m} / \mathrm{z} 251$ exhibited elimination of ethylene to produce a series of ions containing the $\mathrm{SiOH}$ grouping. Only minor direct loss of the ethyl group occurred, e.g. the only ion associated with such loss was that of $\mathrm{m} / \mathrm{z} 267$. Subsequent to, and competitive with loss of ethylene groups elimination of formaldehyde can be observed. The base peak, $\mathrm{m} / \mathrm{z}$ 123 , resulted from loss of all carbon atoms via the two processes noted. Hydroxymethyltrimethoxysilane was prepared by analogous chemistry. It underwent oligomerization and dimerization in methanol similar to the ethoxy compound, but more rapidly with $\sim 70 \%$ conversion to the cyclic dimer, (mass ion 240 by GC-MS).

Hydroxymethylsilanetriol was obtained by hydrolysis of hydroxymethyltrialkoxysilanes. Most of the sol-gel/hydrolysis experiments were performed with a solution containing $50 \%$ ethanol, $\sim 44 \%$ hydroxymethyltriethoxysilane monomer and $\sim 6 \%$ oligomers. Hydroxymethyltriethoxysilane and low-molecular weight alcohol soluble oligomers were readily hydrolyzed to hydroxymethylsilanetriol, which immediately began undergoing autocondensation. Visually, upon mixing with water, turbidity developed and then cleared in minutes to hours depending on the concentration of the silane, alcohol and $\mathrm{pH}$ of the water. This is consistent with the general course of hydrolysis of monoorganotrialkoxysilanes previously described [28] in which the initially immiscible silane hydrolyzed to form soluble silanol containing species. In contrast to most monoorganotrialkoxysilanes and the silicic acid precursor, tetraethoxysilane, the hydrolysis products of hydroxymethyltriethoxysilane had significantly greater solubility and stability in aqueous solutions. The solutions were stable for at least 6 months at concentrations up to $15 \%$ in $1: 1.5$ ethanol-water mixtures at a $\mathrm{pH}$ range of 7-8. In comparison, silicic acid is stable in neutral aqueous solutions only at concentrations below $100 \mathrm{ppm}$. The increased solubility was presumably due to the polarity and hydrogenbonding of the hydroxymethyl group, allowing oligomeric species to remain soluble past the limit of trimeric condensation typically observed for monoalkyltrialkoxysilanes [29]. The increased stability is at least partly due to the reversible condensation of the hydroxymethyl group with silanol. The equilibrium constant for esterification of silanols has been shown to be $\sim 2.5 \times 10^{-2}$ [28], suggesting that the presence of the hydroxymethyl group and hydrolysis and solution ethanol tie-up a sufficient portion of the pool of soluble silicate species to inhibit formation of high molecular weight, insoluble siloxanes. The silanol analog of the cyclic dimer is also likely to have played a role in maintaining water solubility of the hydrolysis products.

The course of hydrolysis was followed in more detail by 29Si NMR. Upon mixing a sample of $50 \%$ hydroxymethyltriethoxysilane with an equal volume of water the resonance at $-52.9 \mathrm{ppm}$ associated with hydroxymethyltriethoxysilane disappeared and was replaced with a multiplicity of resonances ranging from -47.3 to $-75.3 \mathrm{ppm}$ which, in addition to the simple monomer hydroxymethylsilanetriol, may be associated with three main classes of compounds: siloxane bridged and silmethyleneoxide bridged and mixed bridged oligomeric condensates. The NMR of the hydrolysis reaction was distinct from tetraethoxysilane hydrolysis indicating no loss of the hydroxymethylene group (Scheme 2, Fig. 3).<smiles>OC[Si](O)(O)O</smiles>

HYDROXYMETHYLSILANETRIOL<smiles>OC[Si](O)(O)OS(O)(O)CO[Si](O)(CO)CO</smiles>

Scheme 2 Hydroxmethylsilanetriol and condensates 
$-47.3-53.5-56.5-62.3-65.5-72.5-75.3$<smiles></smiles>

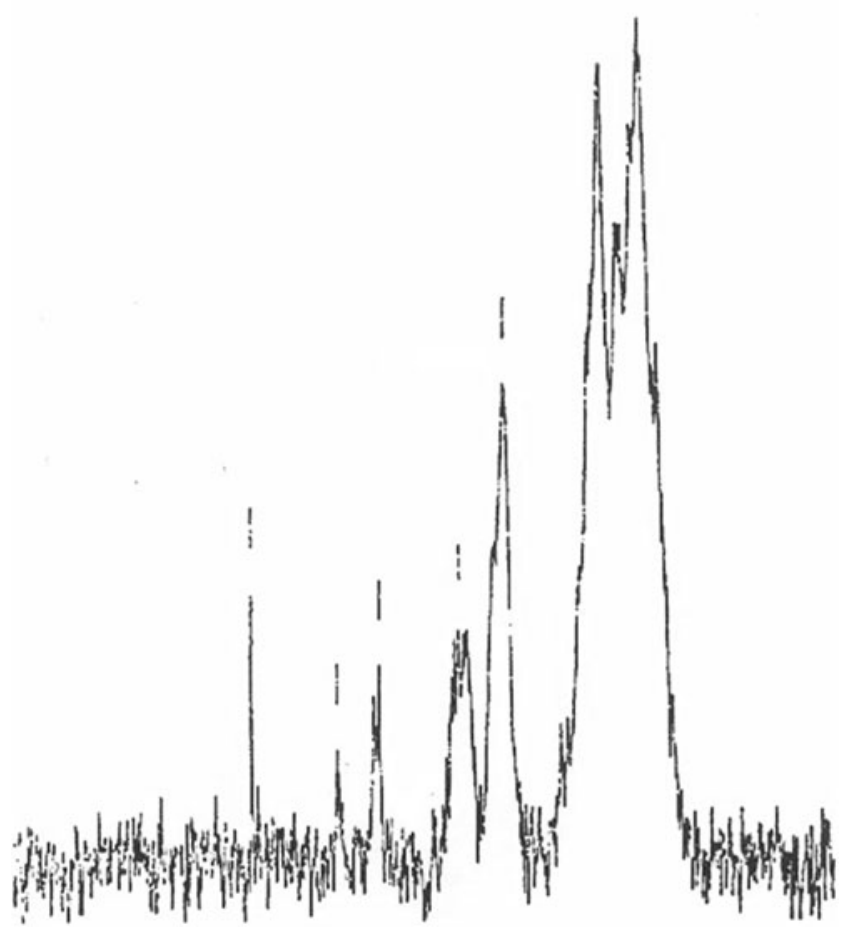

Fig. $350 \%$ Hydroxymethyltriethoxysilane hydrolysate aged 6 days

\subsection{Sol-gel Processing}

Gels formed from hydroxymethyltriethoxysilane when subjected to conditions similar to those described for gel formation of tetraethoxysilane [30]. The dried gels were indefinitely stable to water and, in contrast to gels formed from acetoxymethyltriethoxysilane, did not dissolve in cold sulfuric acid. Thermogravimetric analysis of dried gels derived from hydroxymethyltriethoxysilane in air exhibited less than $5 \%$ of weight loss up to $200{ }^{\circ} \mathrm{C}$, in marked contrast to tetraethoxysilane derived gels which exhibited $15 \%$ weight loss under similar conditions. The hydroxymethyltriethoxysilane derived gels also exhibited less tendency to stress-crack, suggesting that the introduction of the hydroxymethyl group facilitates condensation reactions and allows a pathway for redistribution of covalent network bonds. A char yield of approximately $75 \%$ in air coupled with an elemental analysis of the $800{ }^{\circ} \mathrm{C}$ sintered product with $>99 \% \mathrm{SiO}_{2}$ content indicated full ceramic conversion was facile (Fig. 4, Table 7).

\subsection{Diatom Studies}

The selection of the diatom Cylindrotheca fusiformis for evaluation of hydroxymethylsilanetriol was made based on the relatively large amount of information available on the molecular biology of the species despite its' relatively low level of silicification [31]. Cylindrotheca fusiformis was established in silicon deficient cultures in polycarbonate bottles as previously described [32,33]. Sodium metasilicate and hydroxymethylsilanetriol were freshly prepared as $3.5 \mathrm{mM}$ stock solutions and then introduced to the silicon
Fig. 4

Hydroxymethyltriethoxysilane derived Gel-TGA

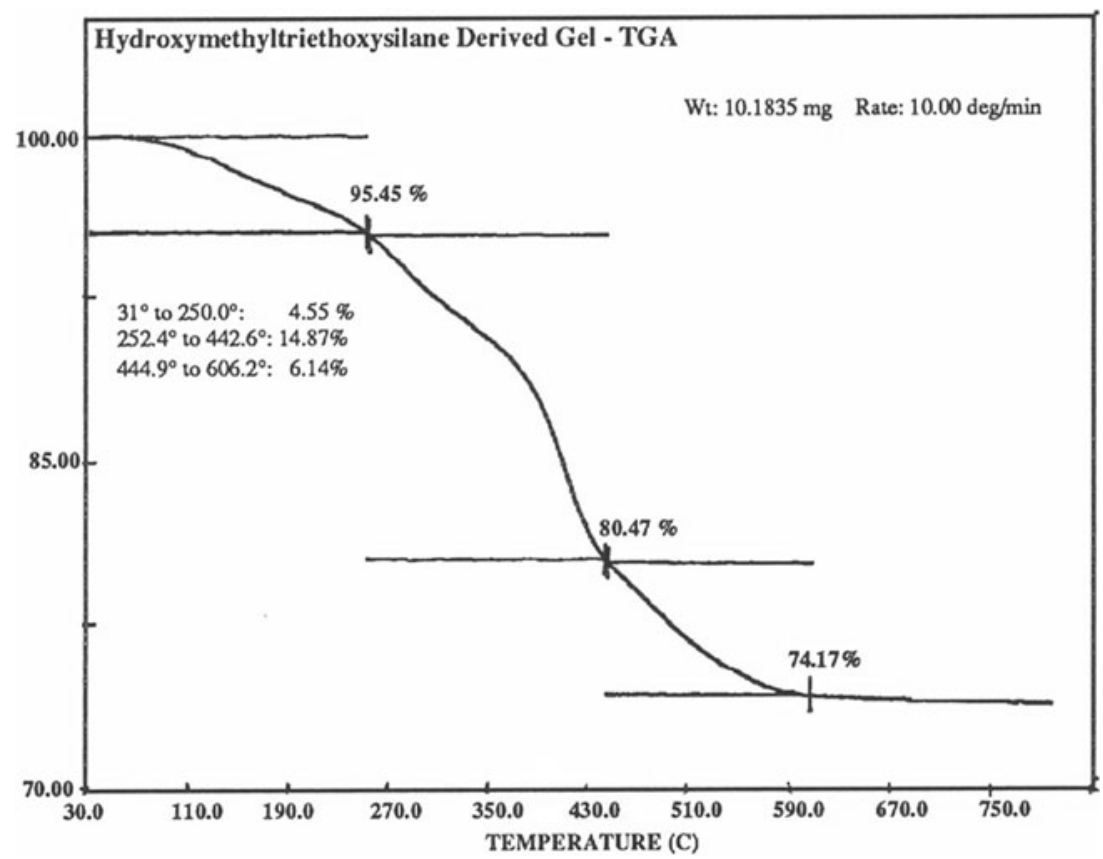




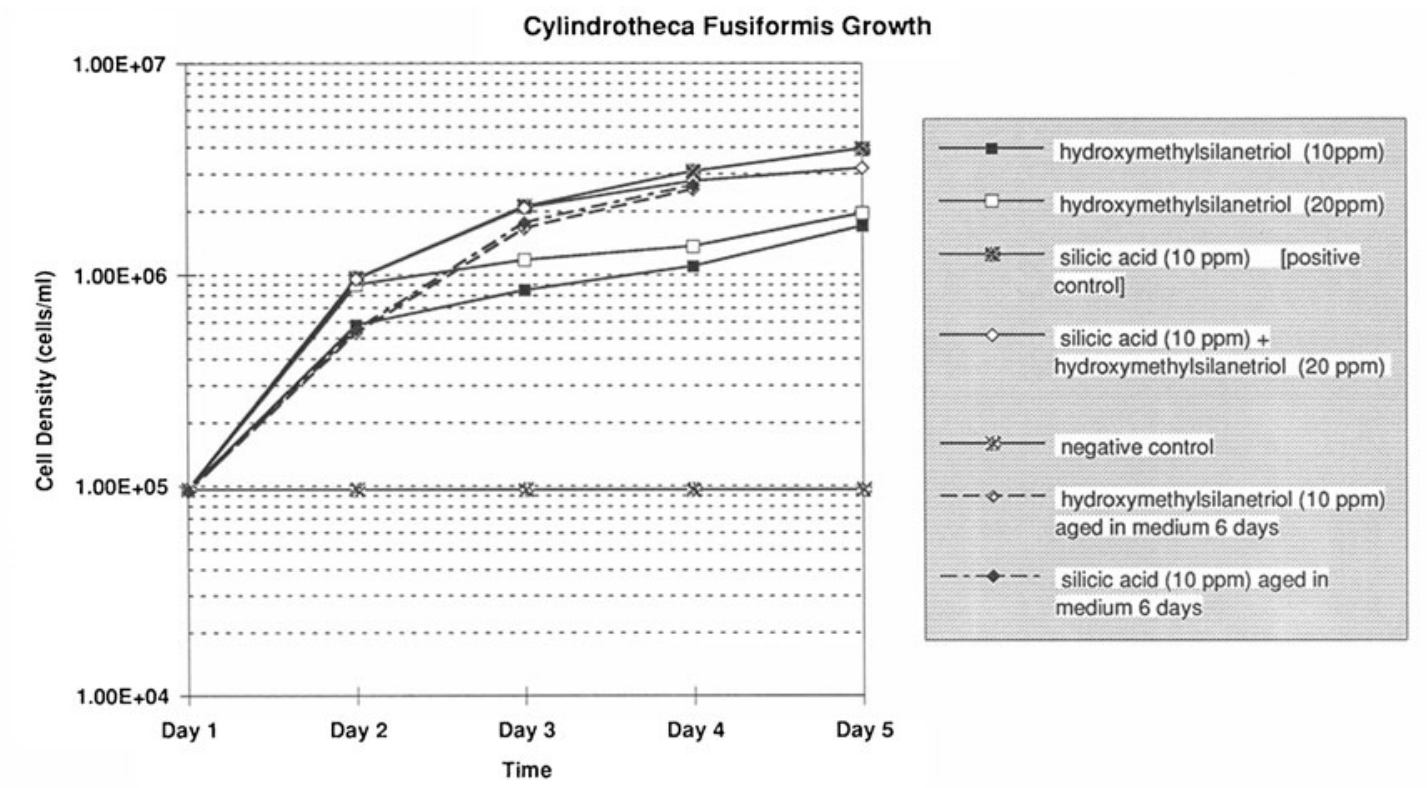

\begin{tabular}{|l|c|c|c|c|c|}
\hline \multicolumn{1}{|c|}{ Compounds: } & Day 1 & Day 2 & Day 3 & Day 4 & Day 5 \\
\hline hydroxymethylsilanetriol (10ppm) & $9.60 \mathrm{E}+04$ & $5.80 \mathrm{E}+05$ & $8.45 \mathrm{E}+05$ & $1.10 \mathrm{E}+06$ & $1.70 \mathrm{E}+06$ \\
\hline hydroxymethylsilanetriol (20ppm) & $9.60 \mathrm{E}+04$ & $9.02 \mathrm{E}+05$ & $1.18 \mathrm{E}+06$ & $1.37 \mathrm{E}+06$ & $1.95 \mathrm{E}+06$ \\
\hline silicic acid (10 ppm) [positive control] & $9.60 \mathrm{E}+04$ & $9.64 \mathrm{E}+05$ & $2.10 \mathrm{E}+06$ & $3.09 \mathrm{E}+06$ & $3.95 \mathrm{E}+06$ \\
\hline silicic acid (10 ppm) + hydroxymethylsilanetriol (20 ppm) & $9.60 \mathrm{E}+04$ & $9.55 \mathrm{E}+05$ & $2.08 \mathrm{E}+06$ & $2.77 \mathrm{E}+06$ & $3.20 \mathrm{E}+06$ \\
\hline negative control & $9.60 \mathrm{E}+04$ & $9.60 \mathrm{E}+04$ & $9.60 \mathrm{E}+04$ & $9.60 \mathrm{E}+04$ & $9.60 \mathrm{E}+04$ \\
\hline hydroxymethylsilanetriol (10 ppm) aged in medium 6 days & $9.40 \mathrm{E}+04$ & $5.33 \mathrm{E}+05$ & $1.66 \mathrm{E}+06$ & $2.54 \mathrm{E}+06$ & \\
\hline silicic acid (10 ppm) aged in medium 6 days & $9.40 \mathrm{E}+04$ & $5.50 \mathrm{E}+05$ & $1.77 \mathrm{E}+06$ & $2.65 \mathrm{E}+06$ & \\
\hline
\end{tabular}

Fig. 5 C. fusiformis culture studies

deficient cultures to give final concentrations of 0-20 ppm. The following compounds were screened in synchronous cultures of C. fusiformis: acetoxymethyltriethoxysilane, sodium carboxyethylsiliconate, sodium hydroxymethylsiliconate, and hydroxymethyltriethoxysilane. As shown in Fig. 5., only hydroxymethyltrethoxysilane demonstrated any effect on the growth rate of cultures. In culture all hydroxymethyltriethoxysilane was assumed to hydrolyze to hydroxymethylsilanetriol. Culture growth was observed at both $10 \mathrm{ppm}$ and $20 \mathrm{ppm}$ levels of hydroxymethylsilanetriol, although at only about $25-30 \%$ of the rate of the silicic acid control. The hydroxymethylsilanetriol appeared to have a small (5-10\%) inhibitory effect on the growth of cultures that were not silicic acid deficient. However, when cultures were introduced into media in which the hydroxymethylsilanetriol had been aged for six days prior to the introduction of the $C$. fusiformis, growth of the diatoms was nearly identical to the silicic acid control. This indicated that the ion-rich culture medium at $\mathrm{pH} 8$ catalyzed the conversion of hydroxymethylsilanetriol to silicic acid. It should be noted that this is potentially a Brook rearrangement [34]. The utilization of hydroxymethylsilanetriol as a substrate for growth of $C$. fusiformis should not be taken as an indication that it is incorporated into the siliceous structure. It is probable that in the culture solution a slow transformation of hydroxymethylsilanetriol to silicic acid occurred which maintained culture growth, but clearly without incorporation of oxymethylene units into the diatom frustule. On the other hand, the inhibitory effect can be explained by inhibition of a protease-type enzyme, perhaps by a mechanism similar to that recently postulated for peptidometic silanediols by Sieburth [35]. Carboxyethylsilanetriol had no effect on cultures either containing or deficient in silicic acid.

\section{Conclusion}

Hydroxymethylsilanetriol is arguably the simplest organosilicon analogous to silicic acid, the monomer for silicate biomineralization. It is prepared by the hydrolysis reaction of hydroxymethyltrialkoxysilanes. Like tetraalkoxysilanes and silicic acid, it undergoes condensation reactions. Hydroxymethyltriethoxysilane, like tetraethoxysilane forms sol-gel type ceramics, but with less potential for stress-cracking during drying. Hydroxymethylsilanetriol interacts with the silicate dependent species $C$. fusiformis behaving as a competitive inhibitor of silicic acid uptake. 
Acknowledgments We would like to remember the late Ben Volcani who performed the initial screening experiments with the diatom $C$. fusiformis and provided insightful discussion.

Open Access This article is distributed under the terms of the Creative Commons Attribution License which permits any use, distribution, and reproduction in any medium, provided the original author(s) and the source are credited.

\section{References}

1. Brinker CJ, Scherer GW (1990) Sol-gel science. Academic Press, New York

2. Schmidt, H (ed) (1998) Sol-gel production. Trans Tech Publications, Uetikon-Zuerich

3. Iler RK (1979) The chemistry of silica. Wiley, New York, p 61

4. Werner D (1977) The biology of diatoms. University of CA Press, Berkeley

5. Sullivan C (1979) J Phycol 15:210

6. Bach K (1984) Diatoms-shells in nature and technics. Institute for Lightweight Structures, Stuttgart

7. Sullivan C (1986) Silicification by diatoms in "Silicon biochemistry" (Ciba Foundation Symposium 121). Wiley, NY, p 50

8. Weiss A, Herzog A (1978) In: Bendz G, Lindquist I (eds) In biochemistry of silicon and related problems. Plenum, NY, p 109

9. Shimizu K, Cha J, Stucky G, Morse D (1998) Proc Nat Acad Sci 95:6234

10. Cha J, Stucky G, Morse D, Deming T (1999) Nature 403:289

11. Brutchey R, Morse D (2008) Chem Rev 108:4915. (and references therein)

12. Poulson N, Sumper M, Kroger N (2003) Proc Nat Acad Sci 100:12075
13. Sumper M, Kroger N (2004) J Mater Chem 14:2059

14. Brott L, Naik R, Pikas D, Kirkpatrick S, Tomlin D, Clarson SJ, Stone M (2001) Nature 413:291

15. Patwardhan SV, Clarson SJ (2003) Inorg Organomet Polymer Mater 13:193

16. Patwardhan SV, Clarson SJ (2005) Chem Commun 41:1113. (and references therein)

17. Dickerson M, Sandhage K, Naik R (2008) Chem Rev 108:4935. (and references therein)

18. Lewin J (1955) Plant Phys 30:129

19. Frampton MB, Zelisko PM (2012) Silicon 4:51. (and references therein)

20. Frampton MB, Zelisko PM (2009) Silicon 1:147. (and references therein)

21. Jakoubkova M, Reish P, Papouskova Z, Pola J, Chvalovsky V (1973) Coll Czechlos Chem Comm 38:3471

22. Paul JS, Volcani BE (1976) Arch Microbiol 110:247

23. Volcani B (1969) Exp Cell Res 58:334

24. Stein J (1979) Handbook of phycological methods, vol 43. Cambridge University Press, p 37

25. Noll JE, Speier JL, Daubert BF (1951). J Amer Chem Soc 73:3867

26. Speier JL (1952) US Pat. 2, 582, 569

27. Petrov AD, Sadykh-Zade SI, Vdvovin VM (1955) Doklady Akademii Nauk SSSR 100:714

28. Arkles B (1977) CHEMTECH 7:766

29. Arkles B, Steinmetz J, Zazyczny J, Mehta P (1992) J Adhesion Sci Technol 6:193

30. Brinker CJ, Keefer KD, Schaeffer DW, Ashley CS (1982) J NonCrystalline Solids 48:47

31. Reeves CD, Volcani BE (1985) J Gen Microbiol 131:1735

32. Paul JS, Volcani BE (1976) Arch Microbiol 110:247

33. Hildebrand M, Crowley DK, Ludwig JR, Kukel A, Feng T, Volcani B (1991) J Bact 173:5924

34. Brook A (1974) Acc Chem Res 7:77

35. Singh S, Sieburth S (2012) Org Lett 14:4422 